\title{
MHD Boundary Layers Due to a Point Sink with Temperature-Dependent Viscosity/Prandtl Number
}

\author{
A. T. Eswara
}

\begin{abstract}
The influence of temperature-dependent viscosity and Prandtl number on the steady, incompressible MHD boundary layer forced flow (of water) due to a point sink is investigated. The coupled non-linear partial differential equations governing the axisymmetric flow are non-dimensionalized into a system of non-linear ordinary differential equations by similarity transformations, and, later solved numerically using an implicit finite difference scheme along with quasilinearization technique. Computations are carried out to examine the effect of various parameters such as transverse magnetic field, temperature-dependent viscosity /Prandtl number on the flow field and heat transfer. From the results of the present study, it has been observed that the effect of magnetic and the variable thermo-physical parameters are considerable and they should to be taken into consideration in the flow and heat transfer problems, arising in engineering and technological applications.
\end{abstract}

Index Terms-Implicit finite-difference scheme, laminar mhd boundary layer flow, point sink, quasilinearization, temperature dependent viscosity/prandtl number.

\section{INTRODUCTION}

Effect of variable fluid parameters on the boundary layer flow and heat transfer is now attracting the attention of researchers owing to its application in technological fields. Indeed, temperature-dependent physical properties like viscosity and thermal conductivity of the fluid play a significant role in fluid mechanics [1]. Consequently, in recent years many studies have been made on the flows with temperature-dependent viscosity in different geometries and under various flow conditions [2]-[9]. Further, boundary layer problems involving magnetic field have become important in contemporary years, in view of the fact that magneto-hydrodynamic (MHD) flows have many major industrial and geothermal applications [10], [11].

Keeping in view the above, the aim of the present investigation is to examine the effects of variable viscosity and Prandtl number on a steady, axisymmetric boundary layer flow of a viscous, incompressible, electrically conducting fluid (water) inside a cone due to a point sink, in presence of transverse magnetic field fixed to the fluid. Both the fluid viscosity and Prandtl number are taken as inverse linear functions of temperature. It is remarked here that Prandtl number is a function of viscosity and as viscosity varies across boundary layer, the Prandtl number varies, too. Since the assumption of constant Prandtl number leads to unrealistic results when viscosity is a strong function of

Manuscript received April 29, 2014; revised June 30, 2014.

A.T. Eswara is with the Department of Mathematics, P.E.S. College of Engineering, Mandya-571 401, India (e-mail: lens10@ymail.com). temperature [12], [13], it is proposed to obtain results when both, viscosity and Prandtl number, are assumed to vary with temperature.

TABLE I: VALUES OF THERMO-PHYSICAL PROPERTIES OF WATER AT DIFFERENT TEMPERATURES [15]

\begin{tabular}{|c|c|c|c|c|c|}
\hline $\begin{array}{l}\text { Temperature } \\
(\mathrm{T})\left({ }^{0} \mathrm{C}\right)\end{array}$ & $\begin{array}{c}\text { Density } \\
(\rho) \\
\left(\mathrm{gr} . / \mathrm{cm}^{3}\right. \\
)\end{array}$ & $\begin{array}{c}\text { Specific } \\
\text { heat }\left(c_{p}\right) \\
(\mathrm{J} \times \\
10^{7} / \mathrm{kg} \\
\left.{ }^{0} \mathrm{~K}\right)\end{array}$ & $\begin{array}{c}\text { Thermal } \\
\text { conducti } \\
\text { vity }(k) \\
(\mathrm{erg} \times \\
10^{5} / \mathrm{cm} . \mathrm{s} \\
\left.-{ }^{0} \mathrm{~K}\right)\end{array}$ & $\begin{array}{c}\text { Viscosit } \\
\mathrm{y}(\mu) \\
(\mathrm{gr} . \times \\
10^{-2} / \\
\mathrm{cm}-\mathrm{s})\end{array}$ & $\begin{array}{c}\text { Prandtl } \\
\text { number } \\
\text { (Pr) }\end{array}$ \\
\hline 0 & 1.00228 & 4.2176 & 0.5610 & 1.7930 & 13.48 \\
\hline 10 & 0.99970 & 4.1921 & 0.5800 & 1.3070 & 9.45 \\
\hline 20 & 0.99821 & 4.1818 & 0.5984 & 1.0060 & 7.03 \\
\hline 30 & 0.99565 & 4.1784 & 0.6154 & 0.7977 & 5.12 \\
\hline 40 & 0.99222 & 4.1785 & 0.6305 & 0.6532 & 4.32 \\
\hline 50 & 0.98803 & 4.1806 & 0.6435 & 0.5470 & 3.55 \\
\hline
\end{tabular}

\section{MATHEMATICAL ANALYSIS}

Consider the steady, laminar axisymmetric flow of a viscous incompressible electrically conducting fluid (water) inside a cone at rest with a hole at the vertex of the cone in presence of uniform transverse magnetic field [See Fig. 1(a)]. In order to treat the boundary layer flow due to the presence of the hole, the hole is regarded as a three dimensional point sink [14]. The cone has been taken as semi infinite in length so that it can be regarded as independent of length $r$. A transverse magnetic field $B_{0}$ is applied in the $z$-direction normal to the cone surface and, it is assumed that the magnetic Reynolds number is small, so that the induced magnetic field can be neglected in comparison of applied magnetic field.The Hall effect and dissipation terms are neglected.The fluid properties are assumed to be isotropic and constant except for the fluid viscosity. The fluid is assumed to flow with moderate velocities, and the temperature difference between the surface of the cone and the free stream is small $\left(<40^{\circ} \mathrm{C}\right)$. In the range of temperature $(T)$ considered (i.e. $0-40^{\circ} \mathrm{C}$ ) the variation of both density $(\rho)$ and specific heat $\left(c_{p}\right)$ of water with temperature, is less than $1 \%$ (See Table I) and hence they are taken as constants. However, since the thermal conductivity $(k)$ and viscosity $(\mu)$ [and hence Prandtl number $(\mathrm{Pr})$ ] variation with temperature is quite significant, the viscosity ( $\mu$ ) and Prandtl number are assumed to vary as an inverse linear function of temperature [5]:

$$
\begin{aligned}
& \mu=1 /\left(b_{1}+b_{2} T\right) \\
& \operatorname{Pr}=1 /\left(c_{1}+c_{2} T\right)
\end{aligned}
$$

where 


$$
b_{1}=53.41, \quad b_{2}=2.43, \quad c_{1}=0.068, \text { and } c_{2}=0.004
$$

The numerical data, used for these correlations, are taken from [15]. The relation (1) and (2) are reasonably good approximations for liquids such as water, particularly for small wall and ambient temperature differences. As the fluid is incompressible, the contribution of heating due to compression is very small and it has been neglected. Under the aforesaid assumptions, the governing equations for steady, forced convection flow using conservation of mass, momentum and energy can be written as

$$
\begin{gathered}
(r u)_{r}+(r w)_{z}=0 \\
u u_{r}+w u_{z}=-\rho^{-1} p_{r}+\left(\mu u_{z}\right)_{z}-\rho^{-1} \sigma B_{0}{ }^{2} u \\
u T_{r}+w T_{z}=\rho^{-1}\left(\operatorname{Pr}^{-1} \mu T_{z}\right)_{z}
\end{gathered}
$$

where

$$
-\rho^{-1} p_{r}=U U_{r}+\rho^{-1} \sigma B_{0}{ }^{2} U, \quad U=-m / r^{2}, m>0 .
$$

The boundary conditions are given by

$$
\left.\begin{array}{l}
u(r, 0)=0 ; w(r .0)=w_{w} ; T(r, 0)=T_{w} \\
u(r, \infty)=U ; T(r, \infty)=T_{\infty}
\end{array}\right\}
$$

Applying the following transformations to (4)-(6), we find that (4) is satisfied identically and (5) and (6) reduce, respectively, to self-similar equations given by

$$
\begin{gathered}
\eta=\left(\frac{m}{2 v r^{3}}\right)^{\frac{1}{2}} z, r u=\frac{\partial \psi}{\partial z} \quad, r w=-\frac{\partial \psi}{\partial r} \\
\psi(r, z)=-(2 v m r)^{1 / 2} f(\eta) \\
u=U F, \quad F=\frac{\partial f}{\partial \eta}, w=\frac{1}{2}\left(\frac{2 m v}{r^{3}}\right)^{\frac{1}{2}}(f-3 F) ; \\
G(\eta)=\frac{T-T_{\infty}}{T_{w}-T_{\infty}} ; M=\frac{2 \sigma B_{0}{ }^{2} r^{3}}{m \rho} \\
\left(N F^{\prime}\right)^{\prime}-f F^{\prime}+4\left(1-F^{2}\right)+M(1-F)=0 \\
\left(N \operatorname{Pr}^{-1} G^{\prime}\right)^{\prime}-f G^{\prime}=0
\end{gathered}
$$

where

$$
\begin{aligned}
& N=\left(\frac{\mu}{\mu_{\infty}}\right)=\frac{b_{1}+b_{2} T_{\infty}}{b_{1}+b_{2} T}=\frac{1}{1+a_{1} G}, \quad \operatorname{Pr}=\frac{1}{c_{1}+c_{2} T}=\frac{1}{a_{2}+a_{3} G}, \\
& a_{1}=\left(\frac{b_{2}}{b_{1}+b_{2} T_{\infty}}\right) \Delta T_{w}, \quad a_{2}=c_{1}+c_{2} T_{\infty}, \\
& a_{3}=c_{2} \Delta T_{w}, \Delta T_{w}=\left(T_{w}-T_{\infty}\right)
\end{aligned}
$$

The transformed boundary conditions are:

$$
\begin{array}{llll}
F=0 ; & G=1 & \text { at } & \eta=0 \\
F=1 ; & G=0 & \text { as } & \eta \rightarrow \infty
\end{array}
$$

Here, $u$ and $w$ are the radial and axial velocities in $r$ and $z$ -directions respectively; $R$ is the radius of the cone ( $R=r \sin \varphi$ ), $\varphi$ is the semi vertical angle of the cone; $T$ is the dimensional temperature; $\psi$ and $f$ are dimensional and dimensionless stream functions, respectively; $F$ and $G$ are the dimensionless velocity and temperature, respectively; $p$ is the static pressure; $\sigma$ is the electrical conductivity; $v$ is the kinematic viscosity; $M$ is the non dimensional magnetic field parameter; $m$ is the strength of the point sink; $U$ is the reference velocity at the edge of the boundary layer and, is a function of $m$; the prime (') denotes derivatives with respect to $\eta$ while, the subscripts $r$ and $z$ denote derivatives with respect to $r$ and $z$, respectively; and, the subscripts $w$ and $\infty$ denote conditions at the wall and in the free stream, respectively.

The skin friction coefficient can be expressed in form and the local heat transfer coefficient in the form of Nusselt number is given by

$$
\begin{gathered}
C_{f}=\frac{2 \tau_{w}}{\rho U^{2}}=2^{1 / 2}\left(\operatorname{Re}_{r}\right)^{-1 / 2}\left(F^{\prime}\right)_{\eta=0} \\
N u=\frac{r q_{w}}{k\left[\left(T_{w}-T_{\infty}\right)\right]}=-2^{-1 / 2}\left(\operatorname{Re}_{r}\right)^{1 / 2}\left(G^{\prime}\right)_{\eta=0}
\end{gathered}
$$

where $\tau_{w}=-\mu\left(u_{z}\right)_{w}, q_{w}=-k\left(T_{z}\right)_{w}$ and $\operatorname{Re}_{r}=\left(\frac{m}{r v}\right)$.

It may be remarked that the above boundary layer approximation is not valid in the immediate neighbourhood of the hole where, in any case, the main- stream flow cannot represent any actual flow through a hole of small but finite diameter [14].

\section{RESUlTS AND DisCUSSION}

The system of ordinary differential equations (10) and (11) along with the boundary conditions (12) using the relations (13)-(14) has been solved numerically using an implicit finite difference scheme along with quasilinearization technique. Since the method is described for ordinary differential equations [16], [17], its description is omitted here for the sake of brevity.

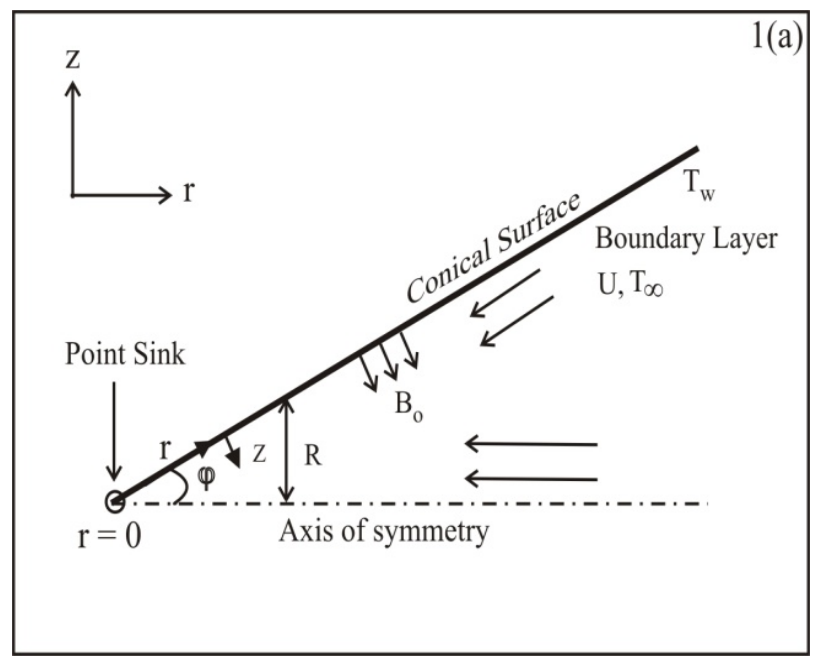




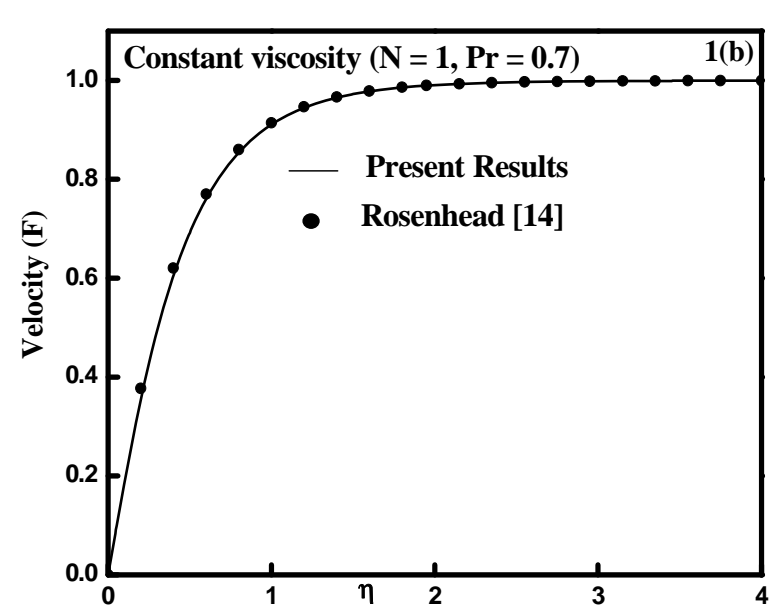

Fig. 1. (a) Flow model and co-ordinate system (b) Comparison of velocity (F) profiles with those of Roseanhead [14].

The skin friction parameter $\left(F^{\prime}\right)_{\eta=0}$ has been computed, for air $(\operatorname{Pr}=0.7)$ with constant fluid properties $(N=1)$ when for $M=0$, and compared with those of [14], and it is found to be 2.2758 as compared to 2.273 given in [14]. Also, pertinent velocity profiles $(F)$ depicted in Fig. 1(b) reveal excellent agreement with [14], validating the accuracy of the numerical method used.
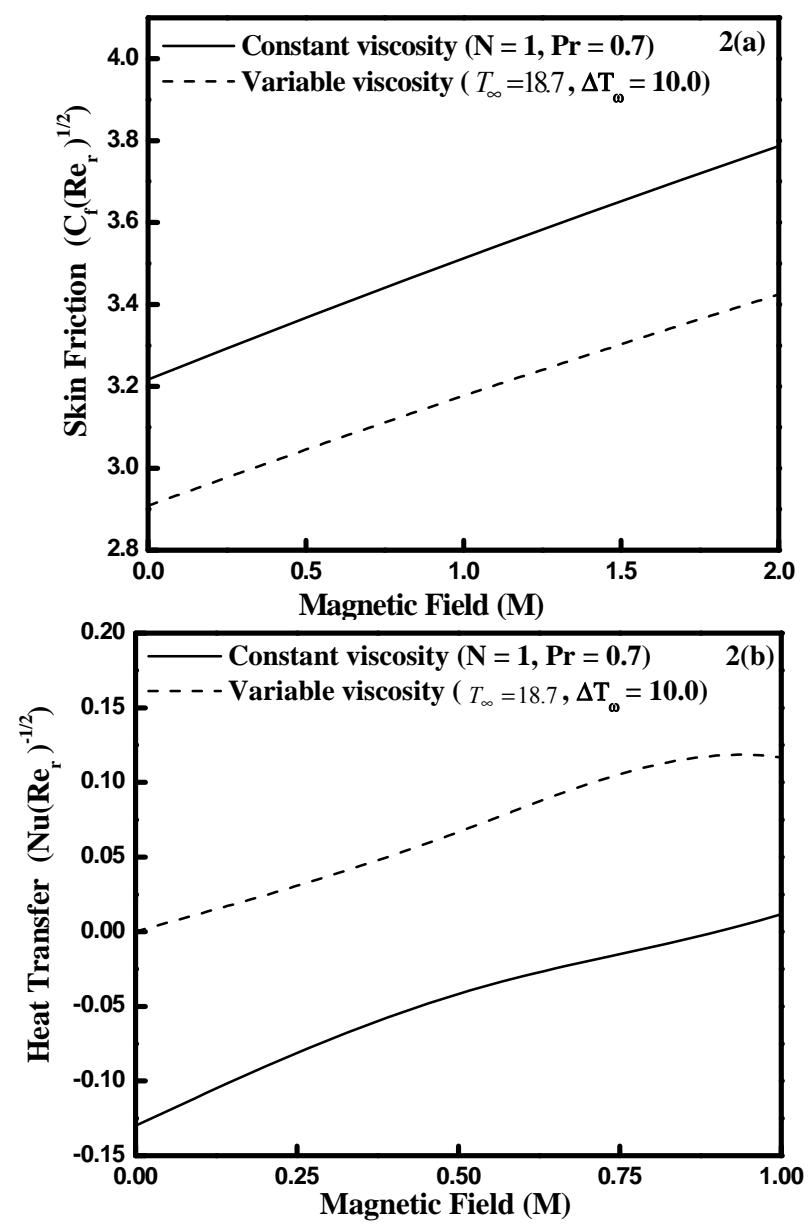

Fig. 2. Effect of magnetic field ( $M$ ) on (a) skin friction and (b) heat transfer coefficients.

The variation of skin friction $\left[C_{f}\left(\operatorname{Re}_{r}\right)^{1 / 2}\right]$ and heat transfer coefficients $\left[N u\left(R e_{r}\right)^{-1 / 2}\right]$ with magnetic field parameter $(M)$ in the presence of variable fluid properties $\left[T_{\infty}=18.7^{\circ} \mathrm{C}, \Delta T_{w}=10.0\right]$ and constant fluid properties $[N=1$ and $\mathrm{Pr}=7.0]$ is shown in Fig. 2. It is observed from these figures that both, $\left[C_{f}\left(R e_{r}\right)^{1 / 2}\right]$ and $\left[N u\left(R e_{r}\right)^{-1 / 2}\right]$ increase with the increase of $M$. However, for a fixed value of $M(\neq 0)$, the effect of temperature-dependent viscosity/Prandtl number is to decrease $\left[C_{f}\left(R e_{r}\right)^{1 / 2}\right]$ and to increase $\left[N u\left(\operatorname{Re}_{r}\right)^{-1 / 2}\right]$. In fact, the percentage of decrease in $\left[C_{f}\left(R e_{r}\right)^{1 / 2}\right.$ ] at $M=0.5$ is $32.23 \%$ [Fig. 2(a)]. On the other hand, the percentage of increase in $\left[N u\left(R e_{r}\right)^{-1 / 2}\right]$ is about $3.00 \%$ (Fig. 2(b)). The relevant velocity $(F)$ and temperature $(G)$ profiles for constant and variable fluid properties are displayed in Fig. 3. It is seen that the velocity profiles increase (Fig. 3(a)) and temperature profiles decrease (Fig. 3(b)) owing to the significant role of temperaturedependent viscosity/Prandtl number inside the laminar momentum and thermal boundary layer.
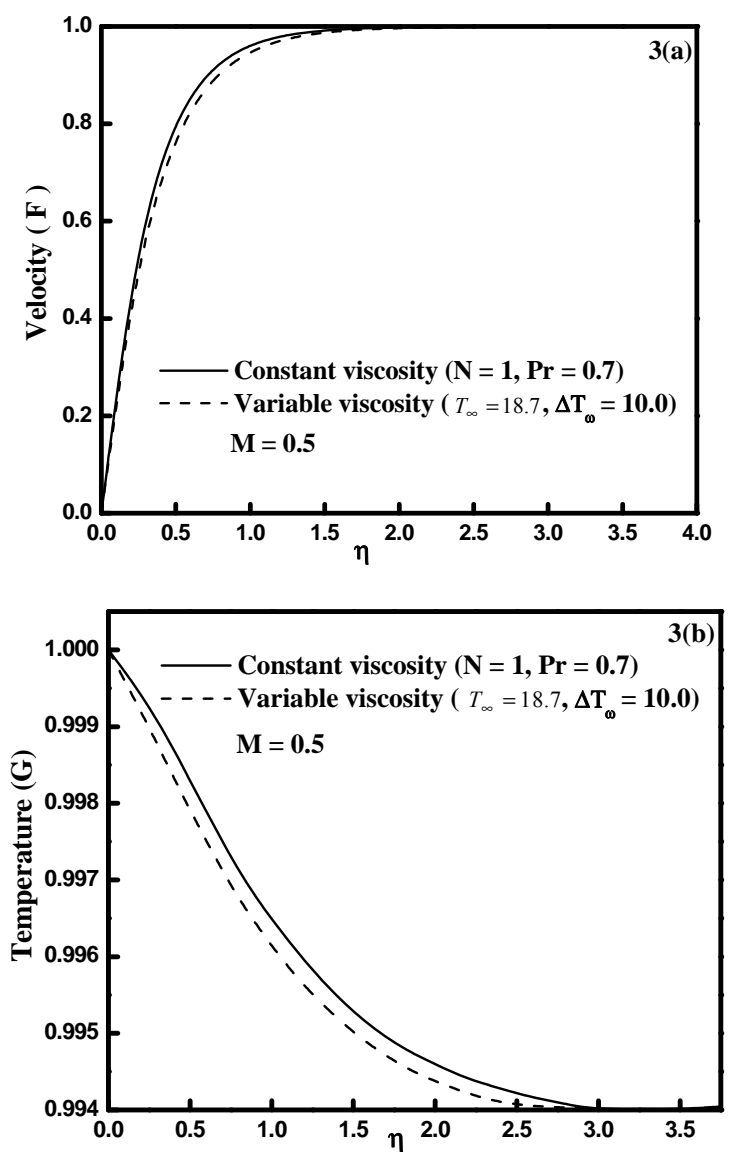

Fig. 3. Effect of magnetic field $(M)$ on (a) velocity and (b) temperature profiles.

To see the effect of difference in the temperature $\left(\Delta T_{w}\right)$ between the wall and fluid, which actually causes the variation of viscosity and Prandtl number with temperature across the boundary layer, the skin friction $\left[C_{f}\left(R e_{r}\right)^{1 / 2}\right]$ and heat transfer $\left[N u\left(\operatorname{Re}_{r}\right)^{-1 / 2}\right]$ coefficients have been plotted against $\Delta T_{w}$ and shown in Fig. 4 . Since $T_{\infty}=18.7^{\circ} \mathrm{C}$, the maximum value of $\Delta T_{w}$ taken is $10^{\circ} \mathrm{C}$ so as to keep the 
temperature within the allowed value $\left(<40^{\circ} \mathrm{C}\right)$, during numerical computations. In this figure we observe that $\left[C_{f}\left(R e_{r}\right)^{1 / 2}\right.$ ] decreases while, $N u\left(\operatorname{Re}_{r}\right)^{-1 / 2}$ increases with the increase of $\Delta T_{w}$, irrespective of whether $M=0$ or $M \neq 0$. Further, it is found that the magnetic field effect $(M \neq 0)$ reduces the heat transfer $\left[N u\left(R e_{r}\right)^{-1 / 2}\right]$ at $\Delta T_{w}=0$ and increases the same, when $\Delta T_{w}$ goes beyond $8^{\circ} \mathrm{C}$, exposing the supremacy of temperature-dependent viscosity/Prandtl number.
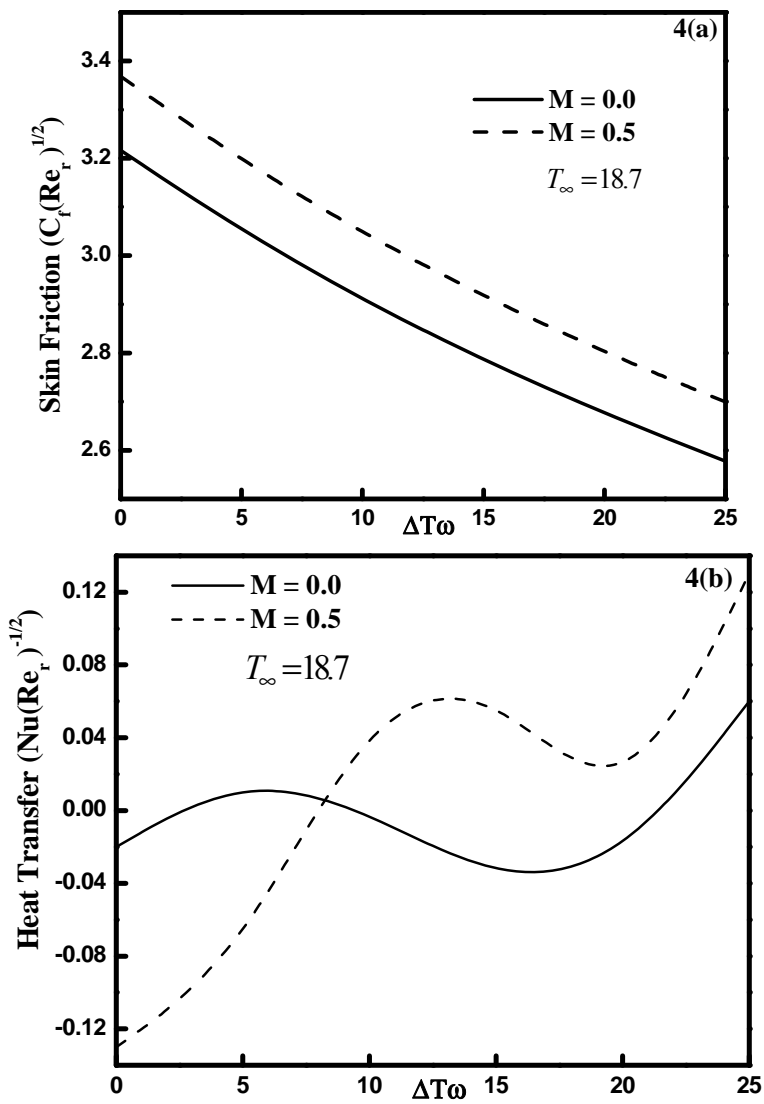

Fig. 4. Effect of $\left(\Delta \mathrm{T}_{\mathrm{w}}\right)$ on (a) skin friction and (b) heat transfer coefficients.

\section{CONCLUSIONS}

Under the assumption of temperature-dependent viscosity/ Prandtl number, the steady MHD laminar water boundary layer flow due to a point sink is numerically investigated. The computed results show that the flow field and thermal characteristics are significantly affected by the temperature-dependent and Prandtl number, in the presence of a transverse magnetic field. From the present study it is concluded that when the viscosity and Prandtl number of a fluid is sensitive to temperature variations it is important to consider the effect of temperature-dependent viscosity/Prandtl number, otherwise substantial errors may occur in the calculations of skin friction factor and heat transfer rate at the wall.

\section{ACKNOWLEDGMENT}

The author is indebted to the management of PET ${ }^{\circledR}$ and authorities of P.E.S. College of Engineering, Mandya- 571 401 for their constant support in his research activities.

\section{REFERENCES}

[1] H. Schlichting and K. Gersten, Boundary Layer Theory, $8^{\text {th }}$ Enlarged ed., McGraw-Hill, New York, 2004.

[2] H. Herwig and G. Wickern, "The effect of variable properties on laminar boundary layer flow," Warme and Stoffubertragung, vol. 20, pp. 47-57, 1986.

[3] I. Pop, R. S. R. Gorla, and M. Rashid, "The effect of variable viscosity on flow and heat transfer to a continuous moving flat plate," Int. J. Engg. Sc., vol. 30, pp. 1-6, 1992.

[4] K. N. Mehta and S. Stood, "Transient free convection flow with temperature-dependent viscosity in a fluid saturated medium," Int. J. Engng. Sci., vol. 30, pp. 1083-1087, 1992.

[5] A. T. Eswara and G. Nath, "Unsteady two-dimensional and axisymmetric water boundary layers with variable viscosity and Prandtl number," Int. J. Engng. Sci., vol. 32, pp. 267-279, 1994.

[6] F. M. Hady, A. Y. Bakier, and R. S. R. Gorla, "Mixed convection boundary layer flow on a continuous flat plate with variable viscosity," Int. J. Heat and Mass Transfer, vol. 31, pp. 169-172, 1996.

[7] N. G. Kafoussius and E. W. Williams, "The effect of temperature-dependent viscosity on the free convective laminar boundary layer flow past a vertical flat plate," Acta Mech., vol. 110, pp. 123-137, 1997.

[8] M. A. Hossian and S. Munir, "Mixed convection flow of a viscous fluid from a vertical flat plate with temperature- dependent viscosity," Int. J. Therm. Sci., vol. 40, pp. 173-183, 2000.

[9] A. T. Eswara and B. C. Bommaiah, "The effect of variable viscosity on laminar flow due to a point sink," Indian J. Pure and Appl. Math., vol. 35, pp. 811-815, 2004.

[10] H. S. Takhar, C. D. Surma Devi, and G. Nath, " MHD flow with heat and mass transfer due to a point sink," Indian J. Pure and Appl. Math., vol. 17, pp. 1242-1247, 1986.

[11] A. T. Eswara, S. Roy, and G. Nath, "Unsteady MHD forced flow due to a point sink," Acta Mechanica, vol. 14, pp. 159-172, 2000.

[12] A. Pantokratoras, "Laminar free convection over a vertical isothermal plate with uniform blowing or suction in water with variable physical properties," Int. J. Heat and Mass Transfer, vol. 45, pp. 963-977, 2002.

[13] H. S. Takhar, A. J. Chamkha, and G. Nath, "Effects of thermo-physical quantities on the natural convection flow of gases over a vertical cone," Int. J. Engng. Sci., vol. 42, pp. 243-256, 2004.

[14] L. Roseanhead, Laminar Boundary Layer, Oxford University Press, Oxford, 1963, pp. 427.

[15] N. B. Vargaftik, Thermo-physical Properties of Liquids and Gases, John Wiley and Sons, Inc., London, 1975.

[16] R. E. Bellman and R. E. Kalaba, Quasilinearization and Nonlinear Boundary Value Problem, Elsevier, USA, 1965.

[17] K. Inouye and A. Tate, "Finite difference version of quasilinearization applied to boundary layer equations," AIAA. Journal, vol. 12, pp. 558-560, 1974.

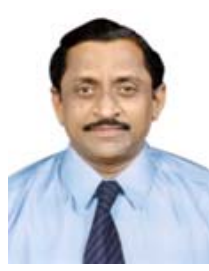

A. T. Eswara is working as a professor in the Department of Mathematics, P. E. S. College of Engineering (PESCE), Mandya-571 401, Karnataka State, in India. He was born in 1955, He obtained his M.Sc. from University of Mysore and Ph.D from Indian Institute of Science, Bangalore. He has more than 34 years of experience in teaching and research. Currently he is working as Dy. Controller of Examinations and Chairman, BOS/BOE in Mathematics, at PESCE.

$\mathrm{He}$ has visited and participated in international conferences at the Universities of New York (USA), Cambridge (UK), Beijing (China), Tokyo (Japan), Kaulalumpur (Malaysia) under financial grant/s from UGC/DST/VTU. His research interests include the areas of Partial Differential Equations, Computational Fluid Mechanics and Boundary Layer Theory. He has published more than 50 research papers in International /National journals and, to his credit 03 students have got Ph.D and 02 have got M.Phil degree.

He has given a number of lectures/presented research papers in conferences held in India and abroad. He has organized number of refresher courses/ seminars sponsored by Government of Karnataka, India. He is Fellow/Member for several academic bodies in India including FSSc., ISTAM, MISTE,VPI. 